\title{
Functional priorities, assistive technology, and brain-computer interfaces after spinal cord injury
}

\author{
Jennifer L. Collinger, PhD; ${ }^{1-3^{*}}$ Michael L. Boninger, MD; ${ }^{1-4}$ Tim M. Bruns, PhD; ${ }^{2}$ Kenneth Curley, MD; \\ Wei Wang, MD, PhD; ${ }^{2-3}$ Douglas J. Weber, $\mathbf{P h D}^{1-4}$ \\ ${ }^{1}$ Human Engineering Research Laboratories, Department of Veterans Affairs Pittsburgh Healthcare System, Pittsburgh, \\ PA; Departments of ${ }^{2}$ Physical Medicine and Rehabilitation, ${ }^{3}$ Bioengineering, and ${ }^{4}$ Rehabilitation Science and Technol- \\ ogy, University of Pittsburgh, Pittsburgh, PA; ${ }^{5}$ U.S. Army Medical Research and Materiel Command, Fort Detrick, MD
}

\begin{abstract}
Spinal cord injury (SCI) often affects a person's ability to perform critical activities of daily living and can negatively affect his or her quality of life. Assistive technology aims to bridge this gap in order to augment function and increase independence. It is critical to involve consumers in the design and evaluation process as new technologies such as braincomputer interfaces (BCIs) are developed. In a survey study of 57 veterans with SCI participating in the 2010 National Veterans Wheelchair Games, we found that restoration of bladder and bowel control, walking, and arm and hand function (tetraplegia only) were all high priorities for improving quality of life. Many of the participants had not used or heard of some currently available technologies designed to improve function or the ability to interact with their environment. The majority of participants in this study were interested in using a BCI, particularly for controlling functional electrical stimulation to restore lost function. Independent operation was considered to be the most important design criteria. Interestingly, many participants reported that they would consider surgery to implant a BCI even though noninvasiveness was a high-priority design requirement. This survey demonstrates the interest of individuals with SCI in receiving and contributing to the design of BCIs.
\end{abstract}

Key words: assistive technology, brain-computer interface, disability, function, functional electrical stimulation, neuroprosthetics, priorities, quality of life, spinal cord injury, veterans.

\section{INTRODUCTION}

Assistive technology aims to augment function for individuals with disability to increase their ability to perform activities of daily living (ADLs) and interact with their environment. Increased access to the environment (measured by the Craig Handicap Assessment and Recording Technique mobility score) is positively associated with life satisfaction [1]. Intuitively, the better an assistive technology meets an individual's needs, the more likely it is to be accepted and utilized. Researchers have increasingly begun to include technology users in the design and evaluation process [2-5]. It has been documented that consumers who feel more informed about an assistive technology are more satisfied with the device [6]. Similarly, when their needs are not met, consumers are less satisfied with the technology [6].

\footnotetext{
Abbreviations: ADL = activity of daily living, ALS = amyotrophic lateral sclerosis, $\mathrm{BCI}=$ brain-computer interface, $\mathrm{FES}=$ functional electrical stimulation, FIM = Functional Independence Measure, $\mathrm{SCI}=$ spinal cord injury, $\mathrm{SD}=$ standard deviation, $\mathrm{VA}=$ Department of Veterans Affairs.

*Address all correspondence to Jennifer L. Collinger, PhD; VA Pittsburgh Healthcare System, Human Engineering Research Laboratories, 6425 Penn Ave, Suite 400, Pittsburgh, PA 15206; 412-822-3700; fax: 412-822-3699.

Email: collingr@pitt.edu

http://dx.doi.org/10.1682/JRRD.2011.11.0213
} 
One emerging field in assistive technology that is starting to undergo limited clinical trials is the brain-computer interface (BCI). BCIs establish a direct link between neural signals generated in the brain and external devices [7-11]. This neural interface technology aims to assist individuals with impaired mobility or communication and has the potential to improve the quality of life of individuals with disabilities. Preclinical experiments in nonhuman primates have demonstrated that information related to intended movement can be extracted from the motor cortex [12-17]. A number of neural recording technologies are being investigated for BCI applications in humans, including scalp electroencephalography [18-20], electrocorticography [2125], and intracortical microelectrode recordings [26-30]. Each recording technique offers advantages and disadvantages in terms of invasiveness, system complexity, and signal quality [8]. While researchers continue to develop these recording methods, it is important to gain insight from potential BCI users about desired functionality and design characteristics.

Here we focus on individuals with spinal cord injury (SCI) while recognizing that people with other disabilities may also benefit from a BCI. Persons with chronic SCI are unique in that their condition tends to be stable and the motor cortex function remains relatively intact [31-32], potentially providing a robust BCI control signal, which has been demonstrated in a few individuals [26-27]. Functional limitations resulting from SCI lead to reduced independence and community participation [33-34]. People with SCI also tend to report a lower quality of life than their nondisabled peers [35-36].

A few studies have examined priorities for functional restoration as defined by individuals with SCI [37-38]. In a survey of 681 individuals with SCI, Anderson reported that arm and hand function was by far the top priority for functional recovery for individuals with tetraplegia [37]. Sexual function was the highest priority for the group with paraplegia. More than 30 percent of people who completed the survey indicated that improvement in bladder and bowel function was the first or second most important priority. Snoek et al. found similar results after surveying 565 members of the Dutch and United Kingdom SCI associations with tetraplegia [38]. Of the respondents, 77 percent indicated that improvement in hand function would result in an important or very important improvement in quality of life. Bladder and bowel function was the next most important factor for this group.
Four previous studies have investigated consumer preferences for neural interfaces, one specifically on BCIs. Huggins et al. surveyed 61 people with amyotrophic lateral sclerosis (ALS) and found that 84 percent would accept an electrode cap for recording brain signals for a BCI [39]. Of the subjects, 72 percent were willing to accept surgically implanted electrodes requiring an outpatient procedure and 41 percent were willing to accept a short hospital stay. Among these subjects, interest was very high (median score 10/10) in 10 different BCI-operated tasks ranging from wheelchair control to light switch operation. Driving a wheelchair and controlling a robotic arm for self-feeding trended toward a more significant interest level than the other tasks. The most important BCI design criteria were accuracy, setup simplicity, standby reliability, and number of available functions. The bar for success was fairly high, with the majority of subjects desiring at least 90 percent accuracy and the ability to communicate at a rate of 15 to 19 letters per minute. This study suggests that people with ALS are interested in using a BCI if it can reliably perform a wide variety of functions in a manner that is superior to existing assistive technologies.

Two of the neural interface studies focused on functional electrical stimulation (FES) for restoration of motor function [40-41]. FES has the potential to restore mobility by stimulating peripheral nerves or muscles to drive patterned muscle contraction. Brown-Triolo et al. conducted telephone interviews with 94 persons with paraplegia and asked them to prioritize the tasks of standing, walking, stair climbing, and transferring [41]. Of the subjects, 66 percent listed walking as the top priority, followed by standing, which was the top priority for 23.4 percent of the subjects. Brown-Triolo et al. also found that subjects were more amenable to implanted technology than visible devices. However, subjects were less likely to indicate that implantation surgery was acceptable.

The fourth study summarized patient preferences for neural prostheses to restore bladder function [5]. Potential side effects were the most significant factor for choosing a neural prosthesis to restore bladder function and continence and voiding effectiveness. The subjects also desired a system with minimally invasive electrodes that could be operated simply by pushing a button. While these studies have addressed the use of peripheral interfaces for restoring function, none have investigated BCI preferences in people with SCI.

The goal of this study was to determine how SCI affects veterans' ability to perform ADLs and to assess their knowledge about currently available assistive technologies 
and clinical interventions designed to increase function. Further, we sought to determine whether they believe BCIs have the potential to increase their function and improve their quality of life. As the rate of technological advancement continues to increase, it is important to include users in the design process so that the technology addresses the current needs and priorities of the consumers.

\section{METHODS}

\section{Survey Design}

We developed a survey to gauge functional priorities, knowledge of technology, and preferences about BCI from veterans with SCI. Nearly 20 percent of the population with SCI in the United States are veterans [42]. We designed the survey based on existing questionnaires [37,43] and with input from all of the article authors as well as local experts in SCI or neural interfaces. The survey included an introductory page that described the purpose of the study, the inclusion criteria, directions for the survey, and a statement that participation was voluntary. The survey is available in the Appendix (available online only).

The first half of the survey assessed demographic information about the sample population as well as the effect of SCI on their function. We collected demographic information on age, injury level, date of injury, education level, and employment. Participants also rated their ability to perform ADLs using a self-report Functional Independence Measure (FIM) [44-45]. The ADLs included eating; grooming; bathing; upper-body dressing; lower-body dressing; toileting; and transferring to a bed, chair, or wheelchair. Participants rated their ability to perform each of these on a scale from 1 (total assistance) to 7 (completely independent). Participants selected a rating of 0 if the activity was not performed. They also reported hours of paid and unpaid assistance.

Additionally, we included a similar question to that asked by Anderson [37]: Which function, if restored, would have the most positive effect on quality of life? The functions included arm and hand function, upperbody and trunk strength and balance, walking movement, bladder and bowel function, sexual function, elimination of dysreflexia, elimination of chronic pain, and normal sensation. Participants ranked the eight functions from most to least important. Participants also rated each item on a scale from 1 (unnecessary) to 5 (very important) in terms of how important improvement in a particular function would be for their quality of life.
The first half of the survey also addressed participants' familiarity with currently available assistive devices and interventions, including FES, hand orthoses, robotic arm assistants, robotically assisted walking training, hand controls for driving, computer access technology, tendon transfer surgery for improved hand function, spinal cord stimulators for pain management, and transcutaneous electrical nerve stimulation. Subjects indicated whether they had used the technology, heard of the technology, or neither. The survey did not include detailed descriptions of these technologies; however, we encouraged participants to ask for clarification if there was any item they did not fully understand.

The second half of the survey focused on BCI technology. We provided a half-page summary of BCI technology and potential applications to establish baseline awareness across the entire sample (Appendix) and asked participants whether they had heard of BCI technology. The next set of questions asked whether or not participants thought they would use a BCI and what types of assistive technology they thought a BCI would be helpful for controlling. Participants assigned ratings of very helpful, somewhat helpful, or not helpful to braincontrolled computers, wheelchairs, robotic assistants, and various FES devices. We also asked which design characteristics would influence their decision about whether or not to use a BCI, using a scale of very important, somewhat important, or not important. The design characteristics included noninvasiveness; setup time; independent operation; training time; cost; number of functions provided; and response time, defined as the time between the command issued by the brain signal and the resulting response of the output device such as a computer cursor. Finally, we asked whether or not participants would be willing to have surgery to implant BCI electrodes and how often they would be willing to come to a laboratory or hospital for training. The survey also included space for open-ended comments related to BCI technology.

\section{Data Collection and Analysis}

We recruited individuals aged 18 or older who had an SCI and spoke English to participate in this paper-based survey as a volunteer sample at the 2010 National Veterans Wheelchair Games in Denver, Colorado. All subjects were participants in the National Veterans Wheelchair Games, which typically attract more than 500 veterans each year. Participants completed the survey anonymously. A research staff member manually input responses into an SPSS database (IBM Corporation; Armonk, New York), 
and the lead author checked them. We conducted descriptive analyses (frequency and mean \pm standard deviation [SD]) using SPSS Statistics 19 (IBM Corporation). We split the study sample by injury level (paraplegia vs tetraplegia) because we expected functional priorities and technology preferences to depend on the level of impairment. We used independent samples $t$-tests to compare age and years with injury between the groups. We used chi-square tests to compare sex and injury classification (complete vs incomplete) between the groups. Missing or invalid responses are noted in the "Results" section. We calculated response rates as a percentage of the total number of valid responses for each question.

\section{RESULTS}

\section{Demographics}

Fifty-seven veterans with SCI completed the survey (Table). Of these, 21 (37\%) had tetraplegia and 36 (63\%) had paraplegia. Injury levels ranged from cervical 3-7

Table.

Demographic information for participants with tetraplegia and paraplegia, $n$ (\%).

\begin{tabular}{|c|c|c|}
\hline Demographic & Tetraplegia & Paraplegia \\
\hline \multicolumn{3}{|l|}{ Sex } \\
\hline Male & $20(95.2)$ & 31 (86.1) \\
\hline Female & $1(4.8)$ & $5(13.9)$ \\
\hline \multicolumn{3}{|l|}{ Injury Classification ${ }^{*}$} \\
\hline Complete & 7 (35.0) & $19(52.8)$ \\
\hline Incomplete & $13(65.0)$ & $17(47.2)$ \\
\hline \multicolumn{3}{|l|}{ Education } \\
\hline Grade 9-11 & - & $1(2.8)$ \\
\hline High School/GED & $14(66.7)$ & $14(38.9)$ \\
\hline Associate's Degree & $1(4.8)$ & 12 (33.3) \\
\hline Bachelor’s Degree & $2(9.5)$ & $4(11.1)$ \\
\hline Master’s Degree & $3(14.3)$ & $3(8.3)$ \\
\hline Doctoral Degree & $1(4.8)$ & $1(2.8)$ \\
\hline Other & - & $1(2.8)$ \\
\hline \multicolumn{3}{|l|}{ Employment } \\
\hline Working & $2(9.5)$ & $2(5.6)$ \\
\hline Homemaker & - & $1(2.8)$ \\
\hline On-the-job Training & - & $1(2.8)$ \\
\hline Retired & $14(66.7)$ & $20(55.6)$ \\
\hline Student & $2(9.5)$ & $2(5.6)$ \\
\hline Unemployed & $1(4.8)$ & $8(22.2)$ \\
\hline Other & $2(9.5)$ & $2(5.6)$ \\
\hline
\end{tabular}

${ }^{*}$ One participant with tetraplegia did not report injury classification. GED = general equivalency diploma.
(C3-C7) for the group with tetraplegia and from thoracic 3-lumbar 4 (T3-L4) for the group with paraplegia. A third of the participants with tetraplegia and half of the participants with paraplegia reported complete injuries. Of the participants with incomplete injuries, 12 were sensory incomplete (5 with tetraplegia) and 16 were motor incomplete (6 with tetraplegia). One participant with tetraplegia reported minimal deficit. Another reported normal motor and sensory function, although it should be noted that all participants used wheelchairs for some of their mobility. On average, the group of veterans with tetraplegia was $55.2 \pm$ $8.3 \mathrm{yr}$ old (mean $\pm \mathrm{SD}$ ) and $22.6 \pm 11.7 \mathrm{yr}$ postinjury. Individuals with paraplegia were $51.3 \pm 12.2$ yr old and $16.2 \pm$ 10.9 yr postinjury. Individuals with tetraplegia were significantly $(p=0.04)$ further out from injury than the group with paraplegia. The Table also presents additional demographic information for the survey population. We found no significant difference in age, sex, or injury classification between the two groups (all $p>0.05$ ).

\section{Assistance with Activities of Daily Living}

More than half (52.3\%) of participants with tetraplegia but less than a quarter (22.2\%) of those with paraplegia reported having paid assistance for self-care activities or mobility. When unpaid assistance was included, 71 percent of participants with tetraplegia and 56 percent with paraplegia typically required some assistance with ADLs. Figure 1 summarizes the percentage of participants who require

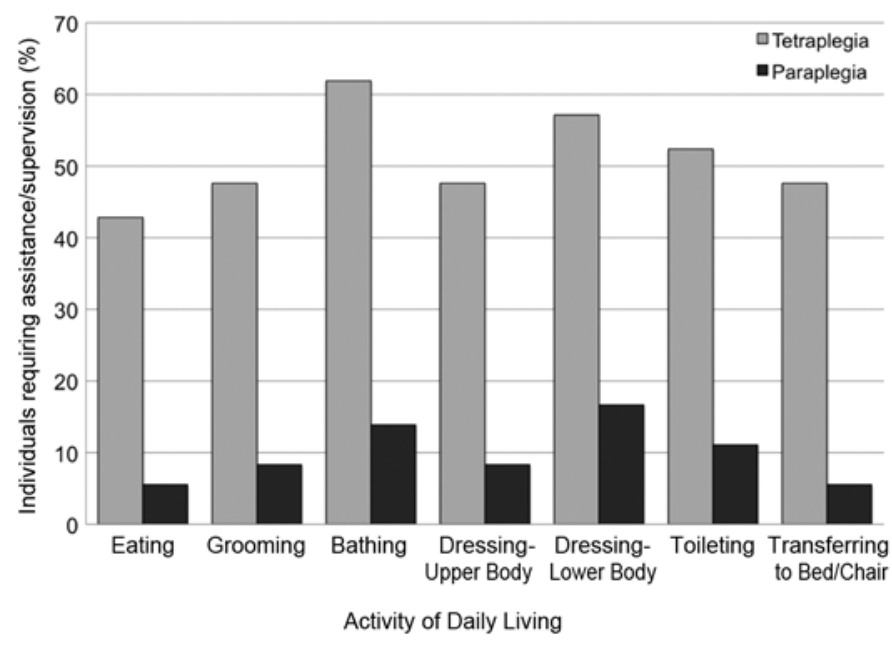

\section{Figure 1.}

Percentage of participants with tetraplegia or paraplegia who report requiring assistance or supervision to complete activities of daily living. 
assistance or supervision to perform seven different ADLs as reported by the FIM. Because of the bimodal distribution of the data, FIM scores of 1 to 5 were collapsed into a single group (requiring assistance or supervision) and scores of 6 and 7 were considered independent performance. On average, approximately half of the participants with tetraplegia reported requiring assistance or supervision with the seven self-care activities compared with only 11 percent with paraplegia. Bathing and lower-body dressing were the two most common tasks requiring assistance for both injury groups.

\section{Experience with Assistive Devices or Interventions}

Figure 2 illustrates the percentage of participants, grouped by injury level, who have used or heard of various assistive devices or clinical interventions. In general, more had used or heard of the technologies than had not. By far, the most commonly used device was hand controls for adapted driving, used by 65 percent of participants with tetraplegia and more than 90 percent with paraplegia. Approximately 40 percent of participants have used FES, which was the next most commonly used technology. We did not distinguish between implanted systems or surface systems. If participants asked for additional clarification, we instructed them that both types of devices were considered FES for the purposes of this survey. Four responses (4 participants, 1 technology each) were missing.

\section{Functional Priorities for Quality of Life}

When asked to rate the importance of functional priorities for improving their general quality of life, more than half of the participants indicated that improvement of each

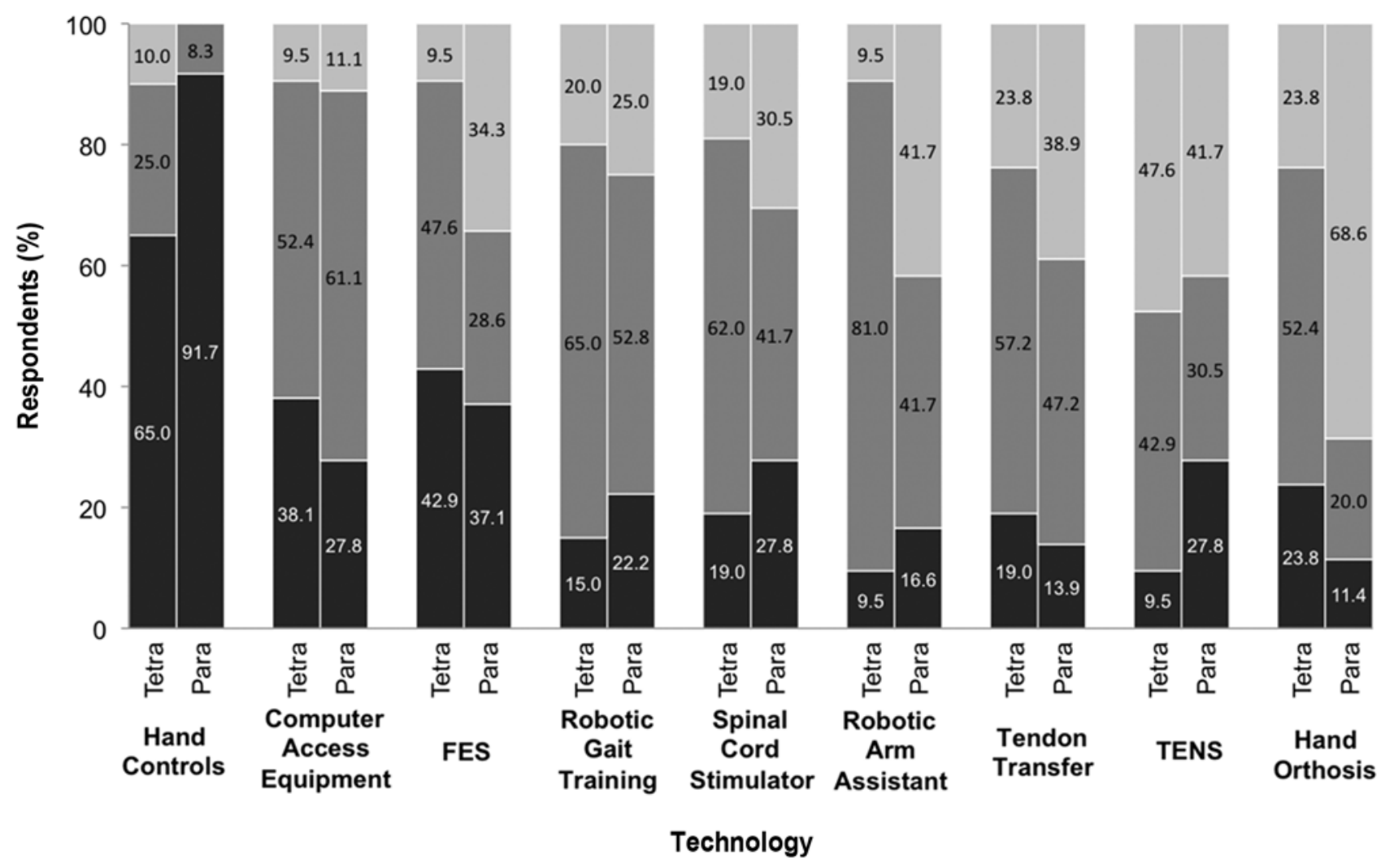

Neither used nor heard of technology

Only heard of technology

Used technology

Figure 2.

Reported experience or familiarity with various assistive devices or clinical interventions. Bar graphs show percentage of participants who had used technology, only heard of technology, or neither. Devices and interventions are ordered from most familiar (left) to least familiar (right) based on average percentage who had neither heard of nor used technology. FES = functional electrical stimulation, para = paraplegia, TENS = transcutaneous electrical nerve stimulation, tetra = tetraplegia. 
of the eight functions was very important (Figure 3). The exceptions were arm and hand function and elimination of dysreflexia among participants with paraplegia and elimination of chronic pain for those with tetraplegia. Very few participants rated any of these functions as unnecessary or not very important. For those with tetraplegia, this ranged from 0 to 4 participants (0\%-19\%) for the eight functions shown in Figure 3. The responses for participants with paraplegia were more variable. The number who rated these functional priorities as unnecessary or not very important were 18 (51\%) for arm and hand function, 6 (17\%) for upper-body function, 3 (9\%) for walking, 1 (3\%) for bladder and bowel function, 5 (14\%) for sexual function, 8 (23\%) for elimination of dysreflexia, 4 (12\%) for elimination of chronic pain, and 2 (6\%) for restoration of normal sensation. One participant with tetraplegia did not provide a response for walking, bladder and bowel func- tion, and dysreflexia; one participant with paraplegia did not answer this question.

In a separate question, participants rated the same eight functions from most to least important in terms of improving quality of life. Of the participants, three with tetraplegia and seven with paraplegia did not respond to this question or did not assign a unique rank to each function, so we excluded their answers. Figure 4 shows the percentage who rated each function as their first or second most important priority. Improvement of bladder and bowel function as well as walking ability was important for both injury groups. Restoration of hand and arm function was a top (first or second highest) priority for approximately half of the participants with tetraplegia. The top priority among those with paraplegia was restoration of walking. For participants with tetraplegia, restoration of bladder and bowel function was most commonly reported as the first or second priority.

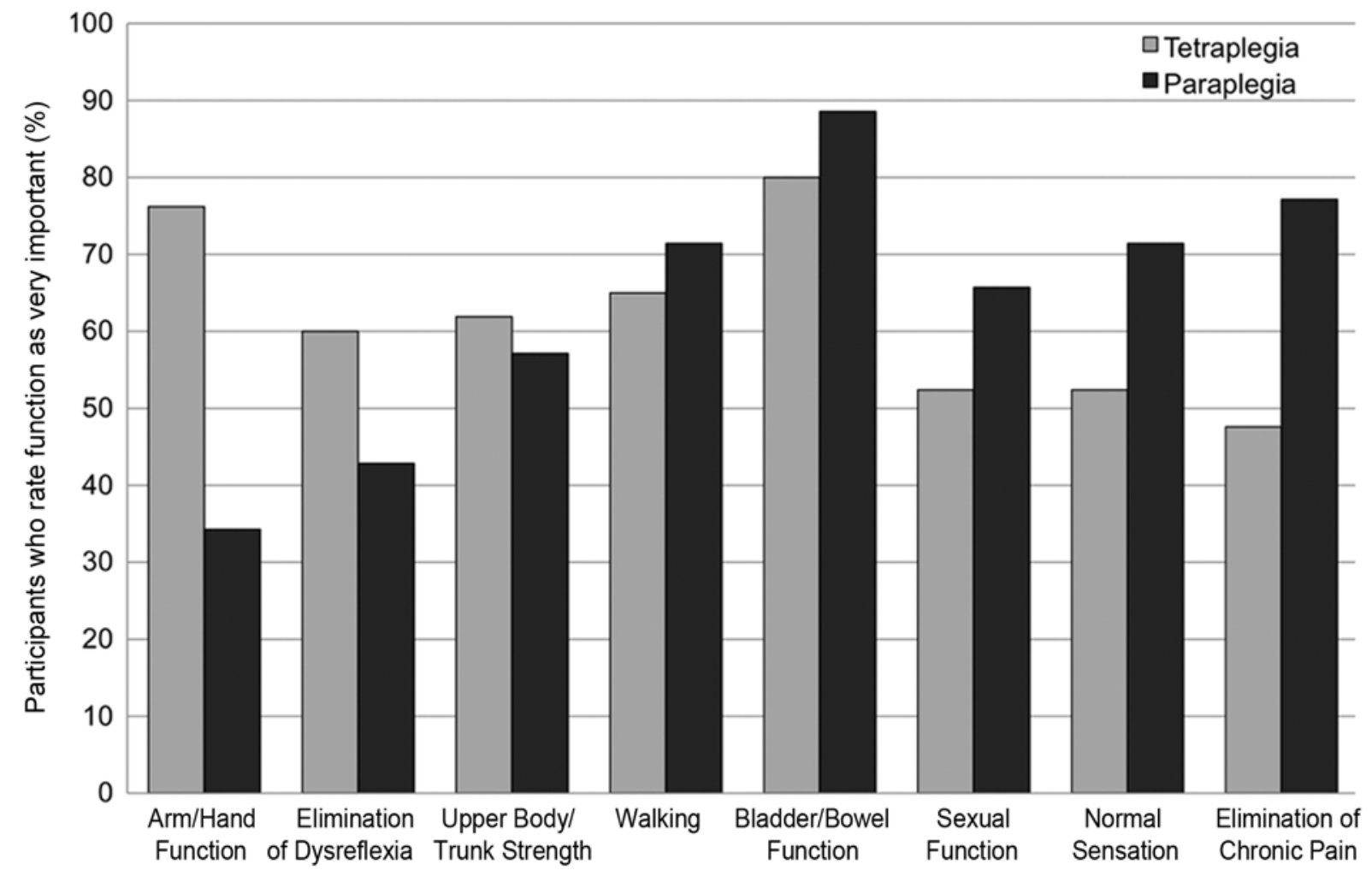

Function

Figure 3.

Percentage of participants with tetraplegia or paraplegia who indicated that restoration of various functions was "very important" for improvement of quality of life. Categories are ordered based on relative difference in importance for participants with tetraplegia compared with those with paraplegia. 


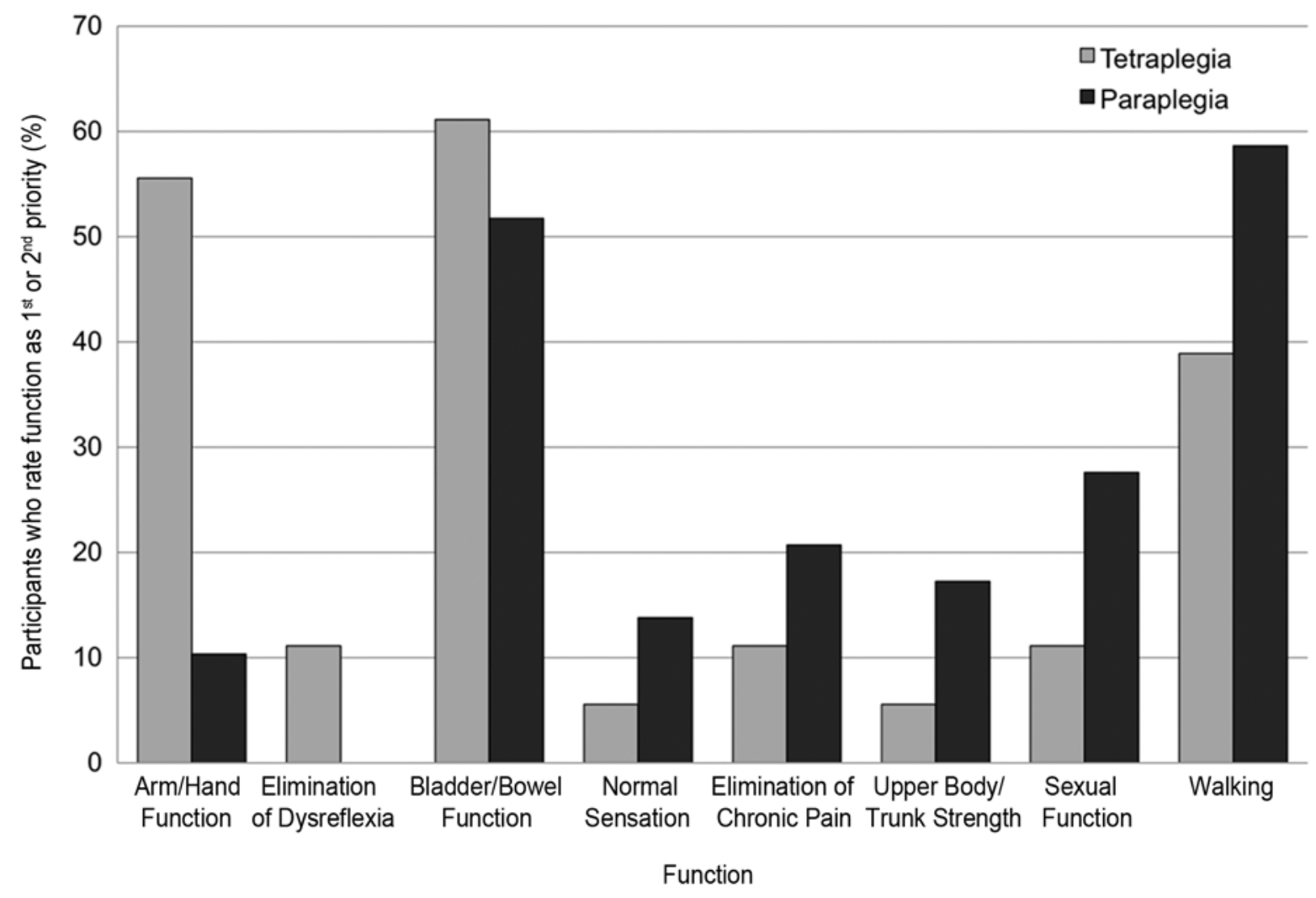

Figure 4.

Percentage of participants with tetraplegia or paraplegia who indicated that restoration of given function was their first or second most important priority for improvement of quality of life. Categories are ordered based on relative difference in importance for those with tetraplegia compared with those with paraplegia.

\section{Brain-Computer Interface Technology}

Of the participants, 75 percent with tetraplegia (15 out of 20) and 53 percent with paraplegia (19 out of 36) reported having heard of BCI technology prior to completing the survey. We provided all participants with a short description of BCI technology before they answered the remainder of the survey questions (Appendix). Of the participants, 18 of 21 with tetraplegia (86\%) and 29 of 36 with paraplegia (81\%) indicated that they would use a BCI to assist with ADLs if it did not inconvenience other aspects of their lives.

Participants rated six technologies in terms of how helpful they thought BCI-control would be: computer, wheelchair, FES for hand grasp, FES for the lower body, FES for bladder and bowel function, and a robotic arm assistant. For each technology, BCI-control could be rated as very helpful, somewhat helpful, or not helpful (Figure 5). One participant with tetraplegia omitted rat- ings for four of the technologies, and three with paraplegia did not provide a rating for each of the technologies. In general, participants considered FES technologies to be best suited for BCI control. As we expected, participants with tetraplegia considered FES for hand grasp more helpful than those with paraplegia. FES for the lower body and bladder and bowel function was equally important to both groups.

Participants also rated the importance of seven BCI design characteristics that they would consider when deciding whether or not to use a BCI. In general, participants rated most of the design characteristics as very important for influencing their decision (Figure 6). Among both injury groups (tetraplegia and paraplegia), independent operation was the most important design characteristic and training time was the least important. In a separate question, we asked participants how often they would be willing to come to a laboratory or clinic 


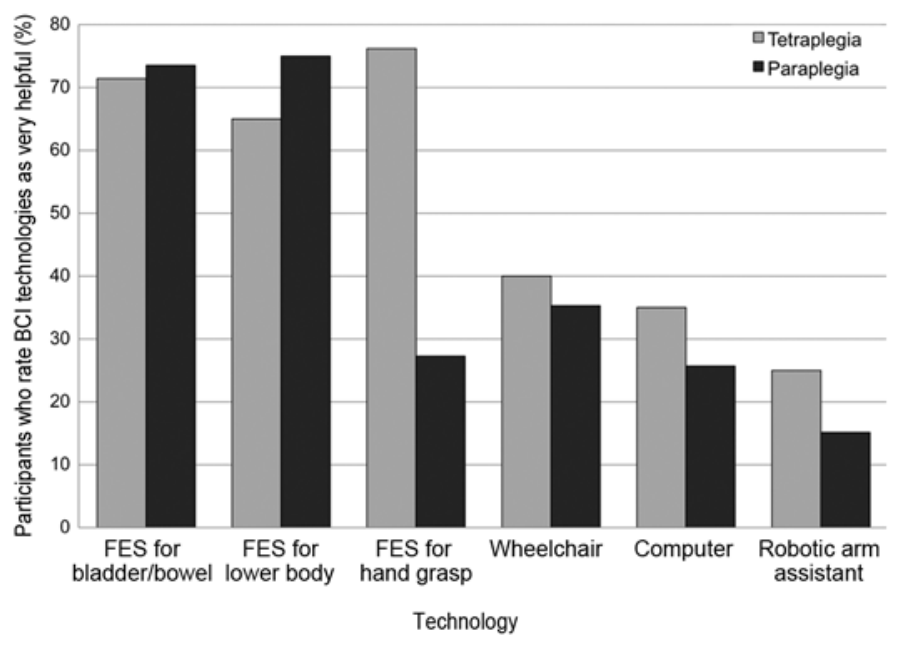

Figure 5.

Percentage of participants with tetraplegia or paraplegia who indicated that brain-computer interface $(\mathrm{BCl})$ control of various technologies would be "very helpful." FES = functional electrical stimulation. for BCI training. Of the participants, 51 percent said that they would come in as often as it took. Once per week (21\%) or two to three times per week $(21 \%)$ were the next most common responses and only one participant said that he or she would not be willing to travel for training. Interestingly, even though more than 70 percent of participants indicated that noninvasiveness was a very important design characteristic, more than half indicated that they would definitely or very likely consider having surgery to implant BCI electrodes (Figure 7).

We provided space for open-ended comments about BCI technology. Nine participants provided comments, of which six expressed a desire to use the technology in the future. One wrote that BCI was a "very cutting edge technology that can benefit many individuals." Another individual commented that the idea of BCI "sounded farfetched" but that he or she "can't wait to see it." Two expressed a particular interest in using a BCI to assist with walking and standing. The other three requested additional information. Two had general requests for

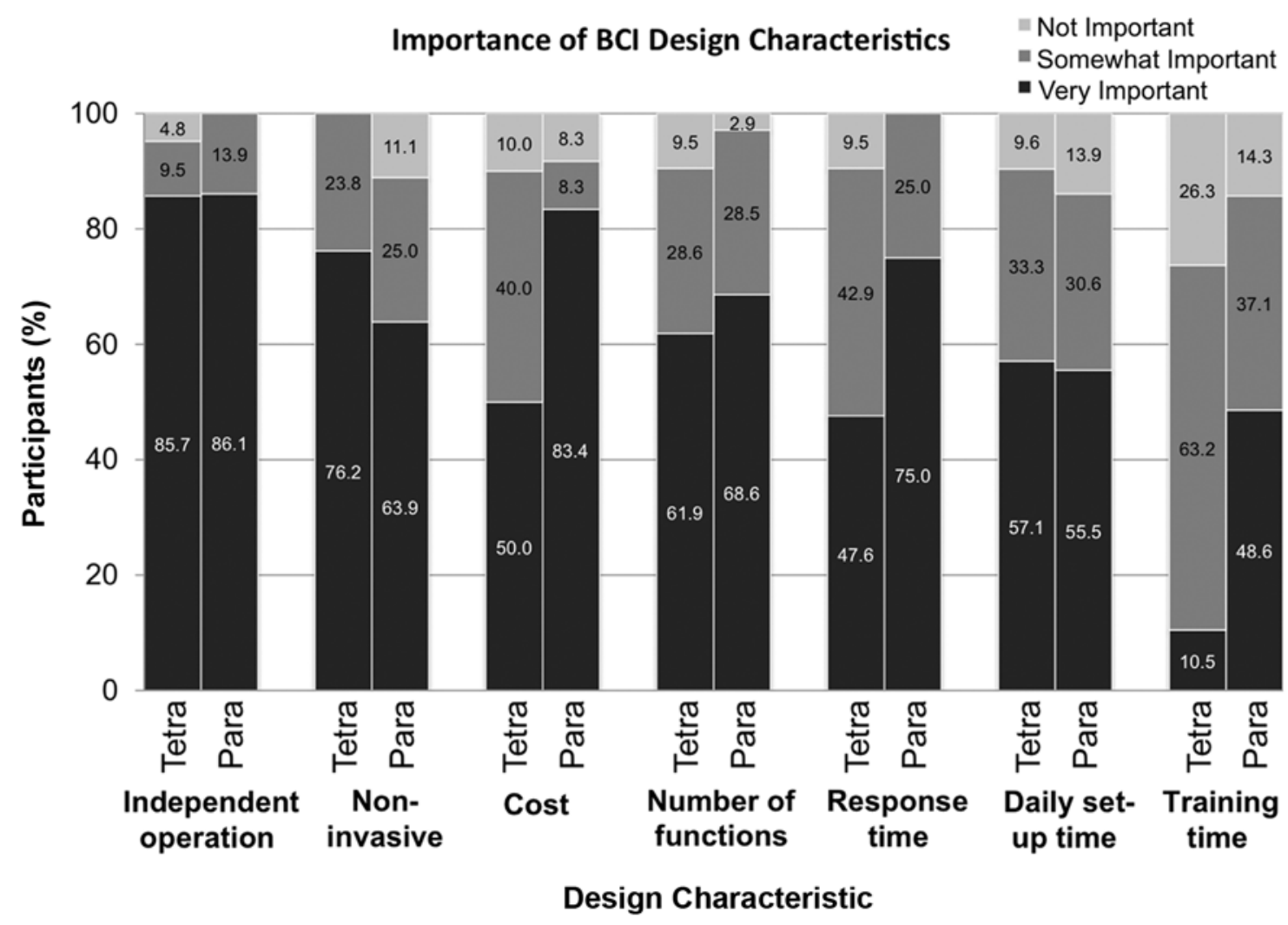

Figure 6.

Reported importance of various design characteristics in deciding whether or not to use brain-computer interface (BCl). Design characteristics are ordered from most important (left) to least important (right) based on average percentage of participants from both groups who ranked characteristics as very important. Para = paraplegia, tetra = tetraplegia. 


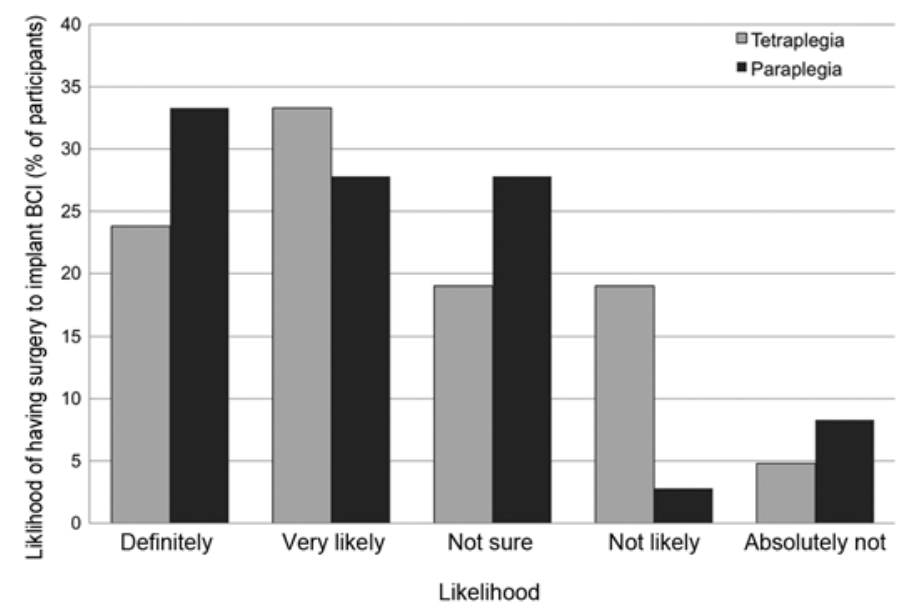

Figure 7.

Likelihood of study participants to have surgery to implant braincomputer interface $(\mathrm{BCl})$ electrodes.

additional information about BCI and one expressed a need to see results from preliminary clinical investigations, particularly regarding safety related to implantation of electrodes, prior to trying the device himself or herself.

\section{DISCUSSION}

A number of investigators have called for greater involvement of individuals with SCI in developing research priorities [4,46-47]. To our knowledge, this is the first study to investigate the priorities of individuals with SCI pertaining to BCI technology. A majority (>80\%) of participants indicated that they would use a $\mathrm{BCI}$ if it did not inconvenience other aspects of their lives. Most felt that BCI would be most useful for controlling FES devices to restore movement or function to their own muscles (Figure 5). The capability for the BCI to be operated independently was the most important design characteristic (Figure 6). Noninvasiveness was also rated as a high priority; however, a majority would consider having surgery to implant a BCI (Figure 7).

All subjects in this study were participants at the 2010 National Veterans Wheelchair Games. Compared with a recent study that described demographic characteristics of the population with SCI in the United States using data from the National Spinal Cord Injury Statistical Center [48], our sample of veterans had a higher percentage of males and was older (Table). This study also included a higher percentage of individuals with paraple- gia and a slightly lower percentage of complete injuries (45\%). In the prevalent population with SCI, approximately 25 percent have more than a high school level education compared with about 50 percent in our sample. The majority of participants in the current study were retired $(n=34)$ or unemployed $(n=9)$. Although community participation was not measured in this study, we speculate that the current sample is at or above the mean level of community participation in the prevalent population with SCI since involvement in the National Veterans Wheelchair Games requires them to travel from across the United States.

In agreement with previous studies [37-38], we found arm and hand function as well as bladder and bowel function to be the most important functional priorities (Figures 3-4). The loss of arm and hand function after cervical SCI limits independence and employment opportunities, increasing the extent, duration, and overall costs of care for persons with tetraplegia [49]. Restoration of walking was a high priority for both injury groups (Figure 3), which is comparable to the results reported by Anderson [37].

The large percentage of individuals with tetraplegia who required assistance with ADLs (Figure 1) is an indication of the inability of current assistive technologies to adequately meet the needs of the population with SCI. In general, our study group was familiar with currently available assistive devices and interventions, although not all were taking advantage of them (Figure 2). A fairly high number of participants ( 40\%) had indicated that they had tried FES. We did not distinguish between implantable or noninvasive systems. Also, for all of the technologies, we did not measure whether participants were currently and routinely using the technology or whether they only had limited experience with it. Many of the participants commented that they had used surface FES as part of therapy or a research study. One potential reason for the low usage rates that we observed is that some devices and interventions are only appropriate for a subsample of the population with SCI. A number of other potential barriers exist to widespread use of this technology, including performance limitations, lack of access or financial resources, and the need for further education of the population with SCI and clinicians. BCI technology may be able to improve the performance of some of these devices and may also provide a more intuitive control interface, particularly for complex technologies. In particular, FES systems and robotic assistants may have many degrees of freedom that 
would be difficult to control with switches, voice control, or other simple interfaces. Human studies of individuals with upper-limb paralysis have shown that neural signals recorded with implanted electrodes can be used to control computer cursors in three dimensions [25] as well as robotic arms to perform reaching and grasping movements [29-30]. In our recent study of a brain-controlled anthropomorphic robotic arm, an individual with tetraplegia was able to control the three-dimensional endpoint velocity of the hand, three-dimensional hand/wrist orientation, and one-dimensional grasp simultaneously at speeds approaching that of a nondisabled person [29].

More than half of the participants had heard of BCI technology prior to completing the survey. Over 80 percent indicated that they would use a BCI to assist with ADLs if it did not inconvenience other aspects of their lives. We view this as a very high percentage, considering that more than half of the participants had paraplegia and that our cohort was older than the prevalent population. A survey of people with ALS also found high interest levels in BCI, with 84 percent accepting electrode caps and 72 percent accepting implanted electrodes requiring outpatient surgery [39]. Previous studies have found that life satisfaction and quality of life improve for individuals with SCI as they age $[47-48,50]$; thus, we expected that they may be less inclined to adopt new assistive technology.

Noninvasiveness, daily setup time, independent operation, cost, number of functions provided, and response time were all felt to be very important design characteristics for a BCI (Figure 6). For participants with tetraplegia, it seems that they were willing to accept a longer training time if the other design criteria were satisfied. These results suggest that BCI users are willing to put in the time to learn how to use the device initially, but they want to minimize the amount of time spent on a daily basis with recalibration or setup. Huggins et al. found a similar preference to minimize setup time among individuals with ALS [39]. Researchers should prioritize the need to identify stable neural features that require infrequent recalibration. Alternatively, it may be possible to develop automated algorithms that adjust the neural decoder during normal BCI operation so that it is transparent to the user. Independent operation of the BCI was the most important factor for both injury groups (tetraplegia and paraplegia). Currently, all BCI systems require some intervention from an operator, either to place the scalp electrodes for each session or to operate the recording hardware and computer that interprets the brain signals into usable control signals. At this stage, most BCIs are oper- ated in laboratory settings and are not yet optimized for home use. Further developments are needed to translate BCIs into clinically viable, independently operated products, including wireless capabilities, improved long-term signal stability and performance, and integration with other assistive technologies [51-52].

Noninvasiveness was also a high priority for this group of potential BCI consumers. The downside of noninvasive systems is that assistance is required to place the electrodes on a daily basis, which is contrary to the users' priority of independent operation. This is similar to the findings of a previous study regarding FES, in which subjects preferred an unobtrusive, implantable system to restore movement but were less open to having surgery to implant the device [41]. The results from Huggins et al. suggest that the length of the postoperative hospital stay influences the degree of acceptance of invasive BCIs [39]. A recent article related to intracortical BCIs discusses the trade-off between invasiveness and burdens and benefits experienced by the user [52]. While a surgical procedure inherently carries risk to the patient, other less obvious negative influences on well-being are also possible for both invasive and noninvasive systems. These include the burden of daily setup, recharging the system, cosmetic burden, and burden on caregivers.

In the ideal scenario, a fully implantable wireless device could safely provide robust control over multiple degrees of freedom without these daily burdens. This ideal system would best meet the needs of the consumer population; therefore, it is important to continue technology development and safety and efficacy testing toward the clinical realization of this type of system. It is important to remember that numerous implantable devices are widely used clinically for treating neurological, motor, cardiac, and other medical conditions. Human testing of implanted BCI systems is currently underway with individuals with disabilities [25,29-30]. We expect that the feedback from these early studies will provide even greater insight into consumer priorities as well as the performance of different types of electrodes and control interfaces.

FES was by far the most popular choice of assistive technology that participants would like to control with a BCI. As expected, priorities for BCI-controlled assistive technology (Figure 5) are well-aligned with priorities for functional restoration (Figures 3-4). FES represents a promising approach for restoring motor function after SCI. Several research groups have demonstrated that useful grasp functions can be restored with FES applied 
through implanted and surface electrodes [49,53-54]. One current limitation of FES, particularly for restoring hand and arm function, is the need for a high-dimensional control signal. BCIs aim to address this gap by providing intuitive and proportional control over multiple dimensions. Additional development and testing of both FES and BCI technologies is required to determine whether a hybrid technology provides functional benefit over simple switch-like control systems. It is unclear from our survey whether BCI-operated FES is any more or less desirable than FES that is operated by another control interface. Despite these limitations, it is still valuable to confirm that restoration of his or her own body function is top priority to a potential consumer. Participants also expressed a strong desire for BCI-controlled FES to improve bladder and bowel function (Figure 5). A BCI may be preferred over an external switch controller for systems that have many degrees of freedom and particularly for systems that involve movement like prosthetics or FES. While a bladder or bowel neuroprosthesis does not necessarily meet this criterion, one can imagine that controlling this device with only 1 or 2 degrees of freedom could be one of many functions provided by a BCI system.

We expected that robotic arm assistants would have a comparable level of interest to FES for hand grasp among individuals with tetraplegia since the goal of these devices is to replace the function of the upper limbs. However, only 25 percent of participants thought that BCI-controlled robotic arm assistants would be very helpful, compared with 75 percent who thought that BCI-controlled FES for hand grasp would be very helpful (Figure 5). An additional 45 percent of study participants with tetraplegia thought that BCI-controlled robotic arm assistants would be somewhat helpful. One possible explanation is that the sample of participants with tetraplegia was not very familiar with robotic arm assistants since 90 percent reported that they had never used these devices. We did not describe a specific robotic arm for participants to evaluate and a wide range of devices are available or in development that have different levels of functionality and aesthetic appeal [55-56]. A great deal of current BCI research is focused on robotic or prosthetic arm control. There are many reasons for this, but one important factor is that robotic technology is capable of producing reliable and complex movements that necessitate a high-dimensional control signal. State-of-the-art implanted FES is capable of restoring simple hand grasps and upper-limb movements depending on a user's level of innervation, but room for improvement remains in terms of movement accuracy, robustness, and dexterity. Another limitation of FES is muscle fatigue since electrical stimulation may result in a reversed recruitment pattern in which large diameter, fatigable muscle fibers are recruited first [57]. Engineers are working to resolve these limitations by combining novel electrode design with optimized stimulation parameters. We suspect that the desire to reanimate one's own limbs is the primary contributing factor for the observed preference of FES over robotic arm assistants. For individuals with SCI, brain-controlled FES should be the highest priority. However, a parallel investigation path is warranted while both BCI and FES continue to mature. Also, among individuals with ALS, interest in BCI-controlled robotic arms was very high [39].

More than 30 percent of participants would consider BCI technology to be very helpful for controlling computers and wheelchairs (Figure 5). This is somewhat surprising since the majority of individuals with paraplegia are likely to use manual wheelchairs. Also, various existing control interfaces exist to provide control of power wheelchairs for individuals with varying levels of impairment. However, one can imagine that it might be desirable to drive a wheelchair or control a seat function intuitively by thought in a manner similar to a nondisabled person controlling his or her own movements. A number of useful computer access technologies are available, but there remains room for improvement [58]. A BCI would have to provide an increase in performance compared with these other technologies in order to be an effective computer access device.

This study was limited to a convenience sample at the National Veterans Wheelchair Games, and thus, the results may not generalize to all veterans or civilians with SCI. The results may be biased since our sample consisted solely of veterans (mostly male) and was older than the prevalent population with SCI. A large percentage of our cohort was retired or not employed and it is unclear whether their disability affected their employment status. It is possible that our sample included people with higher than average levels of community integration since they were all part of a team at their local Department of Veterans Affairs (VA) hospital that travels to this competitive event annually. Also, our sample included more incomplete injuries than the prevalent population so they may have been more independent in performing ADLs (Figure 1).

Although many of the questions allowed the participants to write in additional answers (e.g., technology to be 
controlled by a BCI, important BCI functions), most chose not to do so. Therefore, the survey design limited the potential responses from the participants and important characteristics or priorities were possibly missed. For example, it would be interesting to know how extensively the participants used the various assistive technologies that were presented. Another limitation is that we did not compare the preference for BCI with alternative control interfaces. The effectiveness of the control interface depends on an individual's current level of motor function as well as the complexity of the end effector. It is the responsibility of clinicians and rehabilitation engineers to recommend the most appropriate and safe technology for their patients. The results of this study support the continued development of BCI technology as a potential control interface for complex assistive technologies, particularly those that directly restore motor function. Future studies should be expanded to include nonveterans and individuals with other motor impairments. Additional efforts should be made to include individuals who may be less active in the community than our cohort because they may benefit the most from BCI technology as a way to increase their independence.

\section{CONCLUSIONS}

This was the first study to report priorities for BCI among individuals with SCI. Overall, veterans with SCI felt that BCI would be a useful technology for restoring important motor functions. Independent operation and restoration of one's own motor function were important priorities for BCI design. It is clear that the success of BCI technology depends on effectively integrating with other technologies such as FES in order to improve the user's ability to interact with his or her environment. BCI may be one way to improve environmental access by improving the functionality of other assistive devices that allow for restoration or augmentation of function.

\section{ACKNOWLEDGMENTS}

\author{
Author Contributions: \\ Study concept and design: J. L. Collinger, M. L. Boninger, D. J. Weber. \\ Survey design: J. L. Collinger, M. L. Boninger, T. M. Bruns, K. Curley, \\ W. Wang, D. J. Weber. \\ Analysis and interpretation of data: J. L. Collinger, M. L. Boninger. \\ Drafting of manuscript: J. L. Collinger, M. L. Boninger, T. M. Bruns.
}

Critical revision of manuscript for important intellectual content: J. L. Collinger, M. L. Boninger, T. M. Bruns, K. Curley, W. Wang, D. J. Weber.

Financial Disclosures: The authors have declared that no competing interests exist.

Funding/Support: This material was based on work supported by the VA Office of Research and Development, Rehabilitation Research and Development Service (grant B6789C), and the Paralyzed Veterans of America.

Additional Contributions: The authors would like to thank Ms. Brittany Mitlo for her assistance with the SPSS database and questionnaire design as well as the researchers from the Human Engineering Research Laboratories who assisted with data collection at the 2010 National Veterans Wheelchair Games.

Institutional Review: This study was approved by the institutional review board at the VA Pittsburgh Healthcare System.

Participant Follow-Up: The authors do not plan to inform participants of the publication of this study.

Disclaimer: The views expressed herein are those of the authors and do not reflect the official policy or position of the VA, Department of the Army, Department of Defense, or U.S. Government.

\section{REFERENCES}

1. Richards JS, Bombardier CH, Tate D, Dijkers M, Gordon W, Shewchuk R, DeVivo MJ. Access to the environment and life satisfaction after spinal cord injury. Arch Phys Med Rehabil. 1999;80(11):1501-6. [PMID:10569447] http://dx.doi.org/10.1016/S0003-9993(99)90264-2

2. Sharma V, Simpson RC, LoPresti EF, Mostowy C, Olson J, Puhlman J, Hayashi S, Cooper RA, Konarski E, Kerley B. Participatory design in the development of the wheelchair convoy system. J Neuroeng Rehabil. 2008;5:1. [PMID:18171465] http://dx.doi.org/10.1186/1743-0003-5-1

3. Liu H, Grindle G, Chuang F, Kelleher A, Cooper R, Sieworek D, Smailagic A, Cooper RA. A survey of feedback modalities for wheelchair power seat functions. IEEE Pervasive Comput. 2012;11(3):54-62.

http://dx.doi.org/10.1109/MPRV.2011.20

4. Anderson KD. Consideration of user priorities when developing neural prosthetics. J Neural Eng. 2009;6(5):055003. [PMID:19721182] http://dx.doi.org/10.1088/1741-2560/6/5/055003

5. Sanders PM, Ijzerman MJ, Roach MJ, Gustafson KJ. Patient preferences for next generation neural prostheses to restore bladder function. Spinal Cord. 2011;49(1):113-19. [PMID:20531360] http://dx.doi.org/10.1038/sc.2010.65

6. Martin JK, Martin LG, Stumbo NJ, Morrill JH. The impact of consumer involvement on satisfaction with and use of assistive technology. Disabil Rehabil Assist Technol. 2011; 
6(3):225-42. [PMID:20929425]

http://dx.doi.org/10.3109/17483107.2010.522685

7. Lebedev MA, Nicolelis MA. Brain-machine interfaces: past, present and future. Trends Neurosci. 2006;29(9):536-46. [PMID:16859758] http://dx.doi.org/10.1016/j.tins.2006.07.004

8. Schwartz AB, Cui XT, Weber DJ, Moran DW. Braincontrolled interfaces: movement restoration with neural prosthetics. Neuron. 2006;52(1):205-20. [PMID:17015237] http://dx.doi.org/10.1016/j.neuron.2006.09.019

9. Daly JJ, Wolpaw JR. Brain-computer interfaces in neurological rehabilitation. Lancet Neurol. 2008;7(11):1032-43. [PMID:18835541] http://dx.doi.org/10.1016/S1474-4422(08)70223-0

10. Donoghue JP. Bridging the brain to the world: a perspective on neural interface systems. Neuron. 2008;60(3):511-21. [PMID:18995827] http://dx.doi.org/10.1016/j.neuron.2008.10.037

11. Wang W, Collinger JL, Perez MA, Tyler-Kabara EC, Cohen LG, Birbaumer N, Brose SW, Schwartz AB, Boninger ML, Weber DJ. Neural interface technology for rehabilitation: exploiting and promoting neuroplasticity. Phys Med Rehabil Clin N Am. 2010;21(1):157-78. [PMID:19951784] http://dx.doi.org/10.1016/j.pmr.2009.07.003

12. Vargas-Irwin CE, Shakhnarovich G, Yadollahpour P, Mislow JM, Black MJ, Donoghue JP. Decoding complete reach and grasp actions from local primary motor cortex populations. J Neurosci. 2010;30(29):9659-69. [PMID:20660249] http://dx.doi.org/10.1523/JNEUROSCI.5443-09.2010

13. Georgopoulos AP, Schwartz AB, Kettner RE. Neuronal population coding of movement direction. Science. 1986; 233(4771):1416-19. [PMID:3749885] http://dx.doi.org/10.1126/science.3749885

14. Moran DW, Schwartz AB. Motor cortical representation of speed and direction during reaching. J Neurophysiol. 1999; 82(5):2676-92. [PMID:10561437]

15. Taylor DM, Tillery SI, Schwartz AB. Direct cortical control of 3D neuroprosthetic devices. Science. 2002;296(5574): 1829-32. [PMID:12052948] http://dx.doi.org/10.1126/science.1070291

16. Velliste M, Perel S, Spalding MC, Whitford AS, Schwartz AB. Cortical control of a prosthetic arm for self-feeding. Nature. 2008;453(7198):1098-1101. [PMID:18509337] http://dx.doi.org/10.1038/nature06996

17. Serruya MD, Hatsopoulos NG, Paninski L, Fellows MR, Donoghue JP. Instant neural control of a movement signal. Nature. 2002;416(6877):141-42. [PMID:11894084] http://dx.doi.org/10.1038/416141a

18. Sellers EW, Donchin EA. A P300-based brain-computer interface: initial tests by ALS patients. Clin Neurophysiol. 2006;117(3):538-48. [PMID:16461003] http://dx.doi.org/10.1016/j.clinph.2005.06.027
19. McFarland DJ, Sarnacki WA, Wolpaw JR. Electroencephalographic (EEG) control of three-dimensional movement. J Neural Eng. 2010;7(3):036007. [PMID:20460690] http://dx.doi.org/10.1088/1741-2560/7/3/036007

20. Nijboer F, Birbaumer N, Kubler A. The influence of psychological state and motivation on brain-computer interface performance in patients with amyotrophic lateral sclerosis - a longitudinal study. Front Neurosci. 2010;4:55. [PMID:20700521]

http://dx.doi.org/10.3389/fnins.2010.00055

21. Leuthardt EC, Schalk G, Wolpaw JR, Ojemann JG, Moran DW. A brain-computer interface using electrocorticographic signals in humans. J Neural Eng. 2004;1(2):63-71. [PMID:15876624]

http://dx.doi.org/10.1088/1741-2560/1/2/001

22. Schalk G, Miller KJ, Anderson NR, Wilson JA, Smyth MD, Ojemann JG, Moran DW, Wolpaw JR, Leuthardt EC. Twodimensional movement control using electrocorticographic signals in humans. J Neural Eng. 2008;5(1):75-84.

[PMID:18310813]

http://dx.doi.org/10.1088/1741-2560/5/1/008

23. Blakely T, Miller KJ, Zanos SP, Rao RP, Ojemann JG. Robust, long-term control of an electrocorticographic braincomputer interface with fixed parameters. Neurosurg Focus. 2009;27(1):E13. [PMID:19569888] http://dx.doi.org/10.3171/2009.4.FOCUS0977

24. Vinjamuri R, Weber DJ, Mao ZH, Collinger JL, Degenhart AD, Kelly JW, Boninger ML, Tyler-Kabara EC, Wang W. Toward synergy-based brain-machine interfaces. IEEE Trans Inf Technol Biomed. 2011;15(5):726-36. [PMID:21708506] http://dx.doi.org/10.1109/TITB.2011.2160272

25. Wang W, Collinger JL, Degenhart AD, Tyler-Kabara EC, Schwartz AB, Moran DW, Weber DJ, Wodlinger B, Vinjamuri RK, Ashmore RC, Kelly JW, Boninger ML. An electrocorticographic brain interface in an individual with tetraplegia. PLoS One. 2013;8(2):e55344. Epub 2013 Feb 6. [PMID:23405137]

26. Hochberg LR, Serruya MD, Friehs GM, Mukand JA, Saleh M, Caplan AH, Branner A, Chen D, Penn RD, Donoghue JP. Neuronal ensemble control of prosthetic devices by a human with tetraplegia. Nature. 2006;442(7099):164-71. [PMID:16838014] http://dx.doi.org/10.1038/nature04970

27. Simeral JD, Kim SP, Black MJ, Donoghue JP, Hochberg LR. Neural control of cursor trajectory and click by a human with tetraplegia 1000 days after implant of an intracortical microelectrode array. J Neural Eng. 2011;8(2): 025027. [PMID:21436513] http://dx.doi.org/10.1088/1741-2560/8/2/025027

28. Kennedy PR, Bakay RA. Restoration of neural output from a paralyzed patient by a direct brain connection. Neuroreport. 
1998;9(8):1707-11. [PMID:9665587]

http://dx.doi.org/10.1097/00001756-199806010-00007

29. Collinger JL, Wodlinger B, Downey JE, Wang W, TylerKabara EC, Weber DJ, McMorland AJ, Velliste M, Boninger ML, Schwartz AB. High-performance neuroprosthetic control by an individual with tetraplegia. Lancet. Epub 2012 Dec 13. [PMID:23253623] http://dx.doi.org/10.1016/S0140-6736(12)61816-9

30. Hochberg LR, Bacher D, Jarosiewicz B, Masse NY, Simeral JD, Vogel J, Haddadin S, Liu J, van der Smagt P, Donoghue JP. Reach and grasp by people with tetraplegia using a neurally controlled robotic arm. Nature. 2012; 485(7398):372-75. [PMID:22596161] http://dx.doi.org/10.1038/nature11076

31. Curt A, Bruehlmeier M, Leenders KL, Roelcke U, Dietz V. Differential effect of spinal cord injury and functional impairment on human brain activation. J Neurotrauma. 2002;19(1):43-51. [PMID:11852977] http://dx.doi.org/10.1089/089771502753460222

32. Hotz-Boendermaker S, Funk M, Summers P, Brugger P, Hepp-Reymond MC, Curt A, Kollias SS. Preservation of motor programs in paraplegics as demonstrated by attempted and imagined foot movements. Neuroimage. 2008;39(1): 383-94. [PMID:17919932] http://dx.doi.org/10.1016/j.neuroimage.2007.07.065

33. Kennedy P, Lude P, Taylor N. Quality of life, social participation, appraisals and coping post spinal cord injury: a review of four community samples. Spinal Cord. 2006; 44(2):95-105. [PMID:16130026] http://dx.doi.org/10.1038/sj.sc.3101787

34. Charlifue S, Gerhart K. Community integration in spinal cord injury of long duration. NeuroRehabilitation. 2004; 19(2):91-101. [PMID:15201468]

35. Barker RN, Kendall MD, Amsters DI, Pershouse KJ, Haines TP, Kuipers P. The relationship between quality of life and disability across the lifespan for people with spinal cord injury. Spinal Cord. 2009;47(2):149-55. [PMID:18594553] http://dx.doi.org/10.1038/sc.2008.82

36. Tate DG, Kalpakjian CZ, Forchheimer MB. Quality of life issues in individuals with spinal cord injury. Arch Phys Med Rehabil. 2002;83(12 Suppl 2):S18-25.

[PMID:12474168]

http://dx.doi.org/10.1053/apmr.2002.36835

37. Anderson KD. Targeting recovery: priorities of the spinal cord-injured population. J Neurotrauma. 2004;21(10): 1371-83. [PMID:15672628] http://dx.doi.org/10.1089/neu.2004.21.1371

38. Snoek GJ, IJzerman MJ, Hermens HJ, Maxwell D, BieringSorensen F. Survey of the needs of patients with spinal cord injury: impact and priority for improvement in hand function in tetraplegics. Spinal Cord. 2004;42(9):526-32.

\section{[PMID:15224087]}

http://dx.doi.org/10.1038/sj.sc.3101638

39. Huggins JE, Wren PA, Gruis KL. What would brain-computer interface users want? Opinions and priorities of potential users with amyotrophic lateral sclerosis. Amyotroph Lateral Scler. 2011;12(5):318-24. [PMID:21534845] http://dx.doi.org/10.3109/17482968.2011.572978

40. Kilgore KL, Scherer M, Bobblitt R, Dettloff J, Dombrowski DM, Godbold N, Jatich JW, Morris R, Penko JS, Schremp ES, Cash LA. Neuroprosthesis consumers' forum: consumer priorities for research directions. J Rehabil Res Dev. 2001;38(6):655-60. [PMID:11767973]

41. Brown-Triolo DL, Roach MJ, Nelson K, Triolo RJ. Consumer perspectives on mobility: implications for neuroprosthesis design. J Rehabil Res Dev. 2002;39(6):659-69. [PMID:17943668]

42. QUERI. Spinal cord injury fact sheet [Internet]. Washington (DC): VA Office of Research and Development, Health Services Research and Development Service; 2009 [updated 2012 Apr; cited 2010 Aug 30]. Available from: http://www.queri.research.va.gov/about/factsheets/ sci factsheet.pdf

43. NSCISC National Spinal Cord Injury Statistical Center. National Spinal Cord Injury Database [Internet]. Birmingham (AL): National Spinal Cord Injury Statistical Center; 2011 [cited 2010 May 1]. Available from:

https://www.nscisc.uab.edu/nscisc-database.aspx

44. Grey N, Kennedy P. The Functional Independence Measure: a comparative study of clinician and self ratings. Paraplegia. 1993;31(7):457-61. [PMID:8371936] http://dx.doi.org/10.1038/sc.1993.74

45. Masedo AI, Hanley M, Jensen MP, Ehde D, Cardenas DD. Reliability and validity of a self-report FIM (FIM-SR) in persons with amputation or spinal cord injury and chronic pain. Am J Phys Med Rehabil. 2005;84(3):167-76, quiz 177-79, 198. [PMID:15725790]

46. Abma TA. Patient participation in health research: research with and for people with spinal cord injuries. Qual Health Res. 2005;15(10):1310-28. [PMID:16263914] http://dx.doi.org/10.1177/1049732305282382

47. Hammell KR. Spinal cord injury rehabilitation research: patient priorities, current deficiencies and potential directions. Disabil Rehabil. 2010;32(14):1209-18. [PMID:20131945] http://dx.doi.org/10.3109/09638280903420325

48. DeVivo MJ, Chen Y. Trends in new injuries, prevalent cases, and aging with spinal cord injury. Arch Phys Med Rehabil. 2011;92(3):332-38. [PMID:21353817] http://dx.doi.org/10.1016/j.apmr.2010.08.031

49. Peckham PH, Keith MW, Kilgore KL, Grill JH, Wuolle KS, Thrope GB, Gorman P, Hobby J, Mulcahey MJ, Carroll S, Hentz VR, Wiegner A; Implantable Neuroprosthesis 
Research Group. Efficacy of an implanted neuroprosthesis for restoring hand grasp in tetraplegia: a multicenter study. Arch Phys Med Rehabil. 2001;82(10):1380-88.

[PMID:11588741] http://dx.doi.org/10.1053/apmr.2001.25910

50. Westgren N, Levi R. Quality of life and traumatic spinal cord injury. Arch Phys Med Rehabil. 1998;79(11):1433-39. [PMID:9821906] http://dx.doi.org/10.1016/S0003-9993(98)90240-4

51. Patil PG, Turner DA. The development of brain-machine interface neuroprosthetic devices. Neurotherapeutics. 2008; 5(1):137-46. [PMID:18164493] http://dx.doi.org/10.1016/j.nurt.2007.11.002

52. Gilja V, Chestek CA, Diester I, Henderson JM, Deisseroth K, Shenoy KV. Challenges and opportunities for next-generation intracortically based neural prostheses. IEEE Trans Biomed Eng. 2011;58(7):1891-99. [PMID:21257365] http://dx.doi.org/10.1109/TBME.2011.2107553

53. Prochazka A, Gauthier M, Wieler M, Kenwell Z. The bionic glove: an electrical stimulator garment that provides controlled grasp and hand opening in quadriplegia. Arch Phys Med Rehabil. 1997;78(6):608-14. [PMID:9196468] http://dx.doi.org/10.1016/S0003-9993(97)90426-3

54. Popovic MR, Popovic DB, Keller T. Neuroprostheses for grasping. Neurol Res. 2002;24(5):443-52. [PMID:12117312] http://dx.doi.org/10.1179/016164102101200311

55. Brose SW, Weber DJ, Salatin BA, Grindle GG, Wang H, Vazquez JJ, Cooper RA. The role of assistive robotics in the lives of persons with disability. Am J Phys Med Reha- bil. 2010;89(6):509-21. [PMID:20134305]

http://dx.doi.org/10.1097/PHM.0b013e3181cf569b

56. Harris A, Katyal K, Para M, Thomas J, editors. Revolutionizing prosthetics software technology. IEEE International Conference on Systems, Man, and Cybernetics; 2011 Oct 9-12; Anchorage, AK.

57. Gater DR Jr, Dolbow D, Tsui B, Gorgey AS. Functional electrical stimulation therapies after spinal cord injury. NeuroRehabilitation. 2011;28(3):231-48. [PMID:21558629]

58. Cooper RA, Cooper R. Quality-of-life technology for people with spinal cord injuries. Phys Med Rehabil Clin N Am. 2010;21(1):1-13. [PMID:19951774] http://dx.doi.org/10.1016/j.pmr.2009.07.004

Submitted for publication November 8, 2011. Accepted in revised form June 21, 2012.

This article and any supplementary material should be cited as follows:

Collinger JL, Boninger ML, Bruns TM, Curley K, Wang W, Weber DJ. Functional priorities, assistive technology, and brain-computer interfaces after spinal cord injury. J Rehabil Res Dev. 2013;50(2):145-60. http://dx.doi.org/10.1682/2011.11.0213

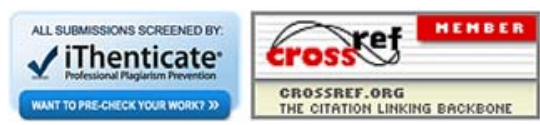


